\title{
Living with Global Climate Diversity-Suggestions on International Governance for Coping with Climate Change Risk
}

\author{
Peijun Shi ${ }^{1,2,3, *}$, Qian Ye ${ }^{1}$, Guoyi Han ${ }^{4}$, Ning Li ${ }^{1,2,3}$, Ming Wang ${ }^{1}$, Weihua Fang ${ }^{3}$, and Yanhua Liu ${ }^{5}$ \\ ${ }^{1}$ State Key Laboratory of Earth Surface Processes and Resource Ecology, Beijing Normal University, Beijing 100875, China \\ ${ }^{2}$ Key Laboratory of Environmental Change and Natural Disasters, Ministry of Education, Beijing Normal University, Beijing 100875 , China \\ ${ }^{3}$ Academy of Disaster Reduction and Emergency Management, Ministry of Civil Affairs and Ministry of Education, Beijing Normal University, \\ Beijing 100875, China \\ ${ }^{4}$ Stockholm Environment Institute, SE-106 91 Stockholm, Sweden \\ ${ }^{5}$ Institute of Geographic Sciences and Natural Resource Research, Chinese Academy of Sciences, Beijing 100101, China
}

\begin{abstract}
Climatic conditions have important influences on human life and the sustainable development of economies and societies. Climate varies in space and time. People have always lived with climate diversity, and the two influence each other. The degree of mutual influence differs at different spatial and temporal scales. Since the industrial revolution, the human effect on climate has gradually increased, and expanded from local to global scale. To allow people to live in harmony with nature and prevent disaster risks, the International Human Dimensions Program on Global Environmental Change (IHDP) announced the implementation of a scientific plan aimed at discussing risk governance, especially with respect to large-scale disaster risks, under global environmental change conditions (IHDP-Integrated Risk Governance Project, 2009-2019). As the initiator of this scientific plan, the authors propose a strategic development framework for living with global climate diversity considering a series of large-scale disasters in China and around the world in recent years and relevant experiences and lessons, and offer suggestions for the global mechanism of dealing with climate change risks.
\end{abstract}

Keywords climate diversity, climate change risk, integrated disaster risk governance, consilience mode of risk governance

\section{Global Climate Diversity}

\subsection{Global Climate Diversity at Different Spatial Scales}

From the perspective of the global spatial scale, Köppen divided the global climate into five climatic zones: Tropical rainy (A), Dry (B), Mild, humid (C), Snowy-forest (D), and Polar (E), and 12 climatic types: Moist forest (Af), Rainforest (Am), Tropical savanna (Aw), Steppe (Bs), Desert (Bw), Mild humid climate with no dry season (C), Mild humid climate

\footnotetext{
* Corresponding author. E-mail: spj@bnu.edu.cn
}

with a dry winter $(\mathrm{Cw})$, Mild humid climate with a dry summer (Cs), Snowy-forest climate with a moist winter (Df), Snowy-forest climate with a dry winter (Dw), tundra (ET), and Perpetual frost (EF) (Strahler and Strahler 1992). This classification mainly relies on temperature and precipitation and refers to plant types. Climate also can be divided into zones and types based on formation causes, emphasizing solar radiation and circulation. Other classification schemes consider the position of eastern and western coasts of continents, oceanic and terrestrial influences, terrain, and other factors in combination with circulating flow. On this kind of basis, Strahler and Strahler (1983) divided the global climate into three zones, 13 types, and 27 subtypes, and Zhou (1997) divided it into three zones and 16 types. The global climate has diverse spatial features (Zhou 1997).

There is also climate diversity at a regional scale. The Physical Regionalization Committee of the Chinese Academy of Sciences classified the climate of China into 7 climate zones, and further divided it into 32 climate types (Huang, Zheng, and Zhao 1999); the China Meteorological Administration classified the climate of China into 10 climate zones, and further divided it into 22 climate types.

There is climate diversity at a local scale as well. Zheng and Li (1999) divided the climate of Mount Everest into seven climate types: low-hill tropical zone, warm mountainous zone, cold mountainous zone, frigid subalpine zone, cold alpine zone, freezing alpine zone, and icy alpine zone. The multiple spatial scales of climate diversity as well as their cross-scale interactions are essential for understanding the patterns and dynamics of climate change risks.

\subsection{Global Climate Diversity at Different Temporal Scales}

On a millennial scale, the global climate has obvious coldwarm and dry-humid oscillations. Climatologists in Norway established a snow line rise-fall diagram for Norway over the 
past 10,000 years (Zhou 1997). According to the diagram, local temperature is higher than current temperature when the snowline is above $1600 \mathrm{~m}$; otherwise, it is cooler than current conditions. Zhu Kezhen constructed an annual temperature variation curve for China over the past 5000 years according to ancient written records and archaeological discoveries, and the curve indicates that the Chinese climate underwent cold-warm oscillations on a millennium scale (Wang 1994).

On a centennial scale, numerous tree ring data indicate that the climate features cold-warm and dry-humid alternations, and goes through varying combinations of temperature and humidity, that is, cold-dry, warm-dry, cold-wet, and warm-wet conditions (Shi, Fang, and Zhao 1989).

On a decadal scale, meteorological observation data indicate cold-warm and dry-humid alternations and fluctuations in climate factors including wind speed, wind direction, air pressure, humidity, visibility, and radiation, which further reflects the diversity of climate (Shi 1989).

An essential characteristic of climate is its diversity at different spatial-temporal scales. This characteristic requires us to fully consider the spatial-temporal scale when coping with various disasters and ecological environment risks due to climate changes. At present, the United Nations does not fully consider climate diversity when formulating global climate change countermeasures. It only establishes internationally unified countermeasures to reduce and adapt to global climate change with conformity at the global spatial scale and centennial time scale, which lacks sensitivity to climate diversity at other scales. There is a need to develop social, political, economic, and ecological measures from the perspective of adaptation to climate diversity by focusing on the reduction and governance of climate change risks at various spatialtemporal scales.

\section{Living with Global Climate Diversity}

\subsection{Relation between Human Activities and Climate}

The relation between human activities and climate is a permanent theme when discussing climate diversity. Before the industrial revolution, this relation was dominated by climate. People's daily lives, social formations, economic structures, local civilizations, languages, art, and other aspects more or less adapted to the climate most of the time. Historical records indicate that climate change can quickly destroy a highly developed and civilized society (Diamond 2005). After the industrial revolution, with the gradual appearance of the effect of carbon dioxide accumulation in the earth's atmosphere and the exponential growth of the global population and economy, the impact of human activities on climate became more and more obvious. The type and magnitude of the impacts of human activities on climate are related to climate diversity as well as the type, extent, and intensity of human activities.
Effect of human activities on atmospheric composition: Many observations show that various trace gas components associated with human activities have been discharged into the air since the industrial revolution, distinctly changing atmospheric composition, especially the proportion of greenhouse gases. A large number of research has shown that the increasing discharge of greenhouse gases by humans is the main cause for the current global climate change, particularly, the increasing global average temperature in the past several decades.

Effect of human activities on the radiance of underlying surfaces: In general, the reflectivity of natural land surfaces depends on the land cover types and their seasonal changes. Reflectivity of land surfaces is strongly dependent on land use and human modification of the natural landscape. For example, cities and towns, mines, and roads increase land surface reflectivity by $5-10$ percent relative to the reflectivity of natural land surfaces (Wu et al. 2000). Land use change greatly affects land surface reflectivity, which in turn affects the amount of solar radiation absorbed by the land surface and the radiant flux of the land surface. Variation in land use is an important reason for the uneven distribution of near-surface temperatures.

Effect of human activities on the dynamic structure of underlying surfaces: The wind dynamic structure of natural land surfaces are closely related to landforms. Land use change greatly affects land surface roughness. In particular, deforestation, reclamation, and urban construction noticeably affect the surface relief and land surface roughness.

Effect of human activities on the thermal performance of underlying surfaces: Human activities affect the amount of surface soil moisture and hence the heat budget and thermal flux of land surfaces. Usually, the less surface soil moisture there is, the lower the thermal flux will be.

In summary, human activities affect the spatial-temporal evolution of the climate system by changing the atmospheric composition, its spatial-temporal distribution, atmospheric radiation, thermal condition, and structure and processes of the underlying surfaces. Activities such as extensive modification of vegetation cover, discharging a great amount of greenhouse gases into the air, tremendously changing land use patterns, and urbanizing vast areas of the landscape not only weaken or strengthen the impact of the climate on people and their activities but also affect the spatial-temporal pattern of the regional or global climate system and climate stability. Humans and climate have established an interdependent system. It is worth to point out, however, that the relationship between humans and climate is going to be changed in the near future. First, with fast development in modern biological engineering technology, which provides possibilities to improve the living environment of animals, plants, and microorganisms in extremely dry areas, extremely cold areas, and places containing very little oxygen, the human survival and development in such areas of extreme climate will be possible. Second, all societies around the world are now 
required to increase the capability of the ecological environment and human society to cope with extreme weather conditions and climate events, such as typhoons, rainstorms, droughts, sandstorms, cold waves, strong winds, and lowtemperature freezing rain and snow. Therefore, it is extremely important to develop various social, economic, political, and technological measures that will improve people's ability to withstand extreme weather and climate events as proposed by the International Strategy for Disaster Reduction (ISDR) of the United Nations (UNISDR 2004) and increase the utilization of extreme-climate areas, in particular, to better adapt to climate diversity on various spatial and temporal scales.

\subsection{Adaptation to Climate Diversity}

As part of their long-term survival, evolution, and development, our human ancestors learned and mastered skills for utilizing climate diversity. Especially in extensive agricultural activities, they fully considered features of climate diversity in space and developed various agricultural production systems, including farming, animal husbandry, and forestry.

Farm work and the design and construction of houses in many areas around the world fully adapt to local climate conditions. For example, in the transitional zone between farming and animal husbandry in Inner Mongolia, China, annual precipitation fluctuates greatly. A production system for alternating farming and animal husbandry was developed to adjust to annual precipitation change (Shi 1989). Today, by developing water-saving irrigation technology, plastic mulching technology, modern biological technology to improve the growth of crops and forest, and various information technologies, we have greatly improved our ability to cope with and adapt to areas of extreme climate and extreme weather and climate events. Existing global measures such as global trades of agricultural products effectively deal with climate diversity in space.

Developments in science and engineering technology also help us adapt to climate diversity on a temporal scale. For example, air conditioners extensively used for production and daily life in cities are applied to adapt to climate diversity on a temporal scale. Comparing with the history of adaptation to climate diversity in space, however, people have accomplished little in adapting on a temporal scale. The main reason is that climate diversity on a temporal scale has obvious uncertainty, thus increasing the difficulty to deal with it.

Climate warming is now generally recognized on the global scale. With warming of the climate, the occurrence frequency, intensity, and duration of extreme weather and climate events will all increase (Meehl et al. 2007), which further challenges the ability of people to cope and adapt their activities. Rare events of low-temperature freezing rain and snow disasters in Europe, Asia, and North America in recent years, heat waves in Europe in 2003 and 2010, and other disasters have greatly affected people's safety and economic security with loss of tens of thousands of lives and damage equating to several hundred billion US dollars (Shi et al. 2008; Lass et al. 2011). Such great loss due to these largescale disasters demonstrates the serious inadequacy of people and their activities in adapting to climate diversity on a temporal scale. The whole world is very susceptible to extreme weather and climate events (IPCC 2007).

In recent years, almost all countries are making great efforts to strengthen their monitoring of climate change, especially in terms of the monitoring, forecasting, and early warning of extreme weather and climate events. These efforts help significantly to reduce casualties when such events happened. Unfortunately, property loss and damage to ecological systems due to extreme weather and climate events are still increasing. It remains a challenge to relieve the enormous pressure of extreme weather and climate events on people and their activities. For small-scale weather events, we can alleviate their impacts to some degree by modifying weather systems artificially. But there is still no effective measure to extensively reduce disasters relating to extreme weather and climate events at large scales. Therefore, our efforts on relieving the negative influence of climate diversity on a temporal scale on people should focus on improving the ability of people and their activities to adapt to climate diversity such as enhancing the defense level, risk transfer, risk awareness, and science and technology for coping with extreme weather and climate events.

To improve the defense level and risk transfer level for extreme weather and climate events, the key is to increase the investment in manpower, build reliable financial structures, and prepare sufficient material supplies. Developed countries can improve risk transfer for extreme weather and climate events through insurance and other financial measures because they have a high defense level. In many developing countries, especially poorer countries and regions, insufficient capital, technology, and human resources make improvements in these areas difficult. Enhancing the levels of defense, risk transfer, risk awareness, and science and technology development for coping with extreme events in these countries and regions is the key to their full adaptation to climate diversity. From the perspective of global natural disaster risk governance, it is essential to fully apply the United Nations International Strategy for Disaster Reduction (UNISDR n.d.), establish a global disaster risk governance union and provide knowledge, technology, and material support to developing countries, especially poor countries, so as to increase their capacity to adapt to climate diversity. At the same time, it is even more important to support the development of these countries in a sustainable way in order to enhance their integrated risk governance capacity (Shi et al. 2011). To do so, it is necessary to establish an integrated disaster risk governance framework with the aim to adapt to climate diversity and especially to improve adaptation in extreme-climate areas and to extreme weather and climate events. 


\section{Development of a Global Climate Change Risk Coping Mechanism}

\subsection{Establishing a Global Integrated Disaster Risk Governance Framework}

According to the consilience model of large-scale disaster (LSD) risk governance (Figure 1) (Shi et al. 2011), it is imperative to improve the global integrated disaster risk governance capability with consideration of the more than 20 years of experiences and lessons of the United Nations in reducing disaster risks (UNISDR n.d.). In this model, we include the responsibilities and rights of stakeholders, the generality and individuality of disasters at different spatialtemporal scales, similarity and differences of socioeconomic systems before, during, and after disasters, and the peculiarities and limitations of different measures. To emphasize crucial actions, simplify common goals, and encourage involvement from all quarters, we propose the establishment of a global integrated disaster risk governance framework in support of development strategies aimed at living with global climate diversity (Figure 2).

Figure 2 shows that there are four aspects to the framework of global integrated disaster risk governance. First, for adapting to global climate diversity, one should consider both spatial scales from global, regional, to local and temporal scales from millennial, centennial, to decadal, as well as the action dimensions that integrate economic, political, cultural, social, and ecological activities. Second, various measures should coexist with global climate diversity, which requires integrating vulnerability-reducing, resilience-improving, and adaptation-enhancing measures. Third, various actions for disaster prevention and reduction as well as disaster risk reduction should be integrated. It is necessary to further integrate the disaster risk reduction structural system to optimize safety fortification, disaster relief and rescue, emergency response, and risk transfer with the disaster risk reduction functional system to complete disaster preparation, emergency response, and restoration and reconstruction. In this way, it is possible to comprehensively improve cohesion in preventing and reducing disaster and mitigating disaster risks and to achieve highly efficient and effective disaster reduction and resource utilization. Fourth, it should allow the necessary adjustment of important disaster reduction strategies that have been implemented around the world in order to complete a global mechanism for coping with climate change risks.

The improvement of the LSD coping ability must include the following activities: (1) to greatly support the promotion

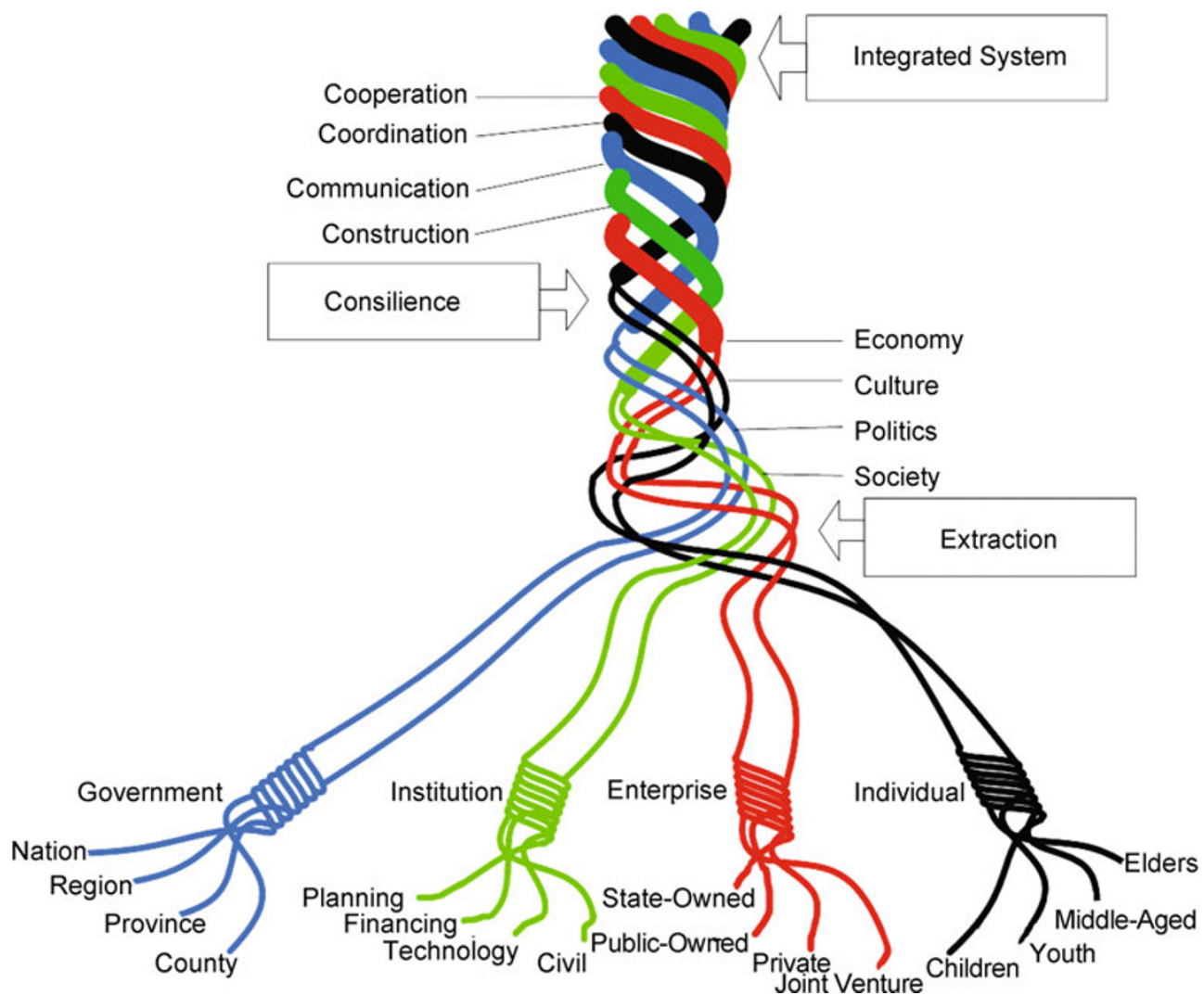

Figure 1. Consilience model of large-scale disaster (LSD) governance

Source: Shi et al. 2011. 


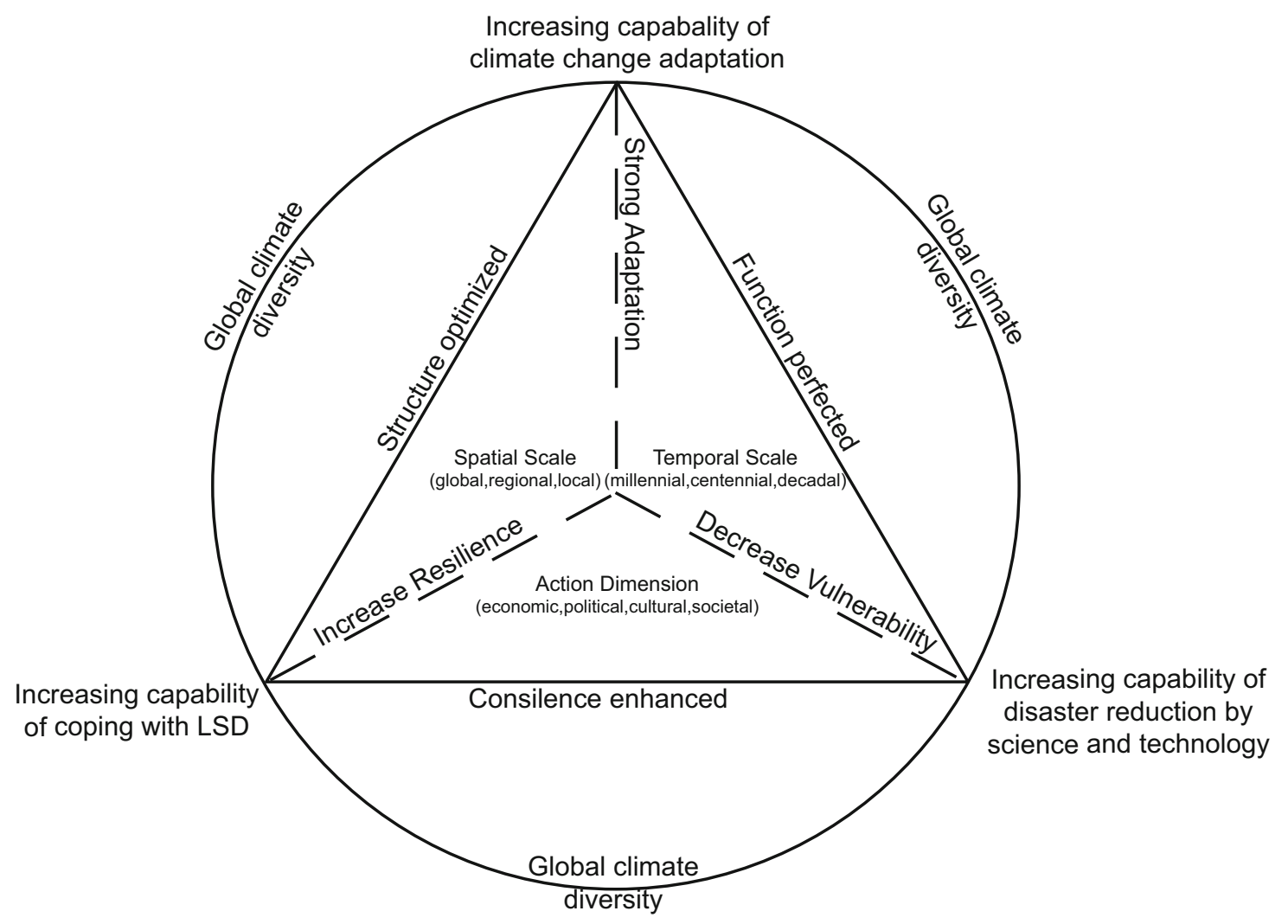

Figure 2. Global integrated disaster risk governance framework in support of the development strategy aimed at living with global climate diversity

and demonstration functions of sharing technology for disaster risk reduction and to complete the LSD risk transfer mechanism; (2) to increase the ability to adapt to climate change by unifying advanced countermeasures and alternative countermeasures and achieve a win-win situation for emission reduction and economic development; and (3) to enhance the science and technology capability for disaster reduction, encourage innovation in education, strengthen scientific research and technology development, and disseminate knowledge and skills for disaster risk prevention. These aspects are interdependent and form the global integrated disaster risk governance framework in support of the strategy aimed at living with global climate diversity. It is our belief that by adopting this framework, the global mechanism for coping with climate change risk can be improved from the perspective of comprehensively alleviating global disaster risks, achieving the millennium development goals proposed by the United Nations, and unifying the current numerous actions of the UN in promoting sustainable development.

\subsection{Suggestions on Improving the Global Mechanism for Coping with Climate Change Risks}

\subsubsection{Establishing a Global Catastrophe Governance Foundation}

To cope with natural disasters, the United Nations has globally sought mitigation measures for natural disasters by executing the International Decade for Natural Disaster Reduction (1989-1999) and the International Strategy of Disaster Reduction (from 2000) (UNISDR n.d.). Although some progresses have been made, as Ban Ki-moon, the Secretary General of the United Nations, has said, the original target of international disaster reduction has still not yet been accomplished and global cooperation in this field needs to be strengthened (Ban 2011).

Following from the consilience model (Shi et al. 2011) for LSD risk governance, similar to the concept of the World Bank and International Monetary Fund supporting world economic development, we propose to form a global catastrophe governance foundation (GCGF) in order to realize a largescale disaster coping strategy of society-wide assistance. The foundation may be managed by the ISDR of the United Nations on behalf of United Nations initially and an international nonprofit organization shall be set up to manage the foundation when the time is suitable. Drawing lessons from current experiences in establishing LSD risk governance funds (bonds) in some countries and regions such as Japan, New Zealand, and Taiwan China, funds for large-scale disasters shall be raised through multifaceted approaches to comprehensively enhance people's LSD coping ability. For example, the United Nations could raise the initial fund according to the gross domestic product (GDP) per capita of all countries. As a rough estimate, a total amount of 18-20 billion US dollars will be levied each year if using 0.1 percent 
of the Chinese per capita GDP as reference, since there are currently over 7 billion people in the world. The foundation will grow by also receiving social donations, expanding funding sources (such as global catastrophe lottery), and introducing market-based instruments. The fund will mainly be used to support each country in promoting and applying various LSD coping technologies as a demonstration, and to promote the free transfer of these achievements to all member countries of the United Nations (countries and regions supplying the foundation funds). The fund can assist member countries of the United Nations in establishing LSD insurance plans and perfecting the global transfer mechanism of LSD risks. Through setting up the GCGF, not only the United Nations' mechanism for ISDR will be further improved, but also the coordination network of the United Nations disaster reduction will be perfected, and the world's comprehensive disaster reduction ability will be enhanced.

\subsubsection{Establishing a Global Green Development Union}

Of the two grand options for reducing greenhouse gases in the atmosphere-reducing emission (source control) and increasing sequestration (sink control), the global focus by far has been much more on the former than the latter. Globally, the fundamental dilemma for carbon emission reduction lies in the fact that, by far in human history, the path of modernization has been unexceptionally linked to emission growth. Consequently, until alternative paths are exemplified, countries, particularly the developing countries, will inevitably fight for their "rights to emit" so to ensure their "rights to develop." This leads to the dismal progress on the global climate negotiation on one hand, and urgent calling and experimentations for low carbon growth on the other. Examples are many, such as circular economy, low-carbon economy, ecological economy, and green development, which are all inter-related notions aiming for a sustainable development pathway in a climate constrained world. In China, energy conservation through improving efficiency and developing renewable energy has been among the top national priorities as a major strategy for achieving energy security and carbon emission reduction.

In contrast, the "sink control" option or offsetting through carbon sequestration has been much less explored, at least at the global policy level. As major drivers of long-term global climate patterns and diversities, change and variability in land use and the resulting impacts on carbon balance remain poorly recognized (Pielke 2005). At a fundamental level, $\mathrm{CO}_{2}$ is the main material source of photosynthesis in the ecological system and its concentration directly affects the strength of photosynthesis. Within a certain scope, the strength of photosynthesis increases with a rise in $\mathrm{CO}_{2}$ concentration (Wu et al. 2000). It is thus plausible for a wide range of biotic carbon sequestration measures, such as developing high capacity carbon-storing vegetation through modern biological technologies. Those biotic carbon sequestration measures combined with land use planning can maximize the ecosystem services in offsetting carbon emissions into the atmosphere, at the same time, improve the environment and promote economic development. If "source control" by reducing emissions into the atmosphere is a "blue" strategy, then "sink control" by increasing ecosystem carbon absorbing capacity is a truly "green" strategy.

To promote such an ecosystem and land use based green strategy to cope with climate change risk, we propose to establish a global green development union aiming at strengthening the infrastructure of the global ecological system. Together with the emission reduction based blue strategy, enhancing the "green" biotic carbon sequestration capacity must be an integral part of the new development pathway for living with climate change risk.

Establishment of a global green development union requires us to integrate several unidirectional actions for promoting sustainable development including the Global Climate Change Convention, Convention to Combat Desertification, Convention on Biological Diversity, Global Wetlands Protection Convention, and International Strategy for Disaster Reduction advocated by the United Nations at present. We need to form a consilience strategy for coping with climate change risks under the lead of the United Nations and participation of national governments, extensively absorb all public, collective, and private resources beneficial for green development, and promote harmony between humans and earth and the unity of nature, so as to create a good living environment for human society. It is imperative to strive for innovation of biological technology, utilize the extensive space of global extreme-climate (for example, low temperature, dry, and anoxia) areas, energetically establish green vegetation, cultivate soil with high-carbon storage capability, and form an ecological system containing more carbon. In this way, it will be possible to return the carbon storage capability of the natural ecological systems occupied by urban use, agricultural production, and industrial use to the earth, and realize the goal of harmony between humans and the earth and a basic balance between carbon emissions and storage by people.

\subsubsection{Establishing a Global Climate Change Risk Education and Research Network}

Improving the ability to cope with global climate change risks, especially LSD risks, not only needs physical, technological, and economic strengths but also requires better comprehension, awareness, and technology of disaster risk governance. At present, relevant organizations of the United Nations such as the United Nations International Strategy for Disaster Reduction, government organizations of countries around the world, risk management enterprises, research institutions, social organizations, and other groups have established different disaster information network platforms and played important roles in disaster education and risk awareness training. However, there is no global climate change risk education and research network at present that meets all requirements owing to differences in language, 
culture, economic benefits, technological levels, standard specifications, and many other reasons. Therefore, we need to fully utilize the leading function of the United Nations ISDR and the established Global Platform for Disaster Risk Reduction (UNISDR n.d.), and closely cooperate with related data and information platforms created by the worldwide insurance industry (for example, transitional direct insurance companies, reinsurance companies, and intermediary companies), national governments, scientific research and higher education institutes, and social organizations. The goal is to form a unified standard and normative global climate change risk education and research network and establish a global network of education and a research platform for coping with global climate change risks through co-development and sharing. We need to form a university union for integrated risk governance, to strengthen disaster prevention and reduction education; a scientific research union for integrated risk governance, to strengthen research and technical development for disaster prevention and reduction; and a community union for integrated risk governance, to strengthen the dissemination and communication of disaster prevention and reduction knowledge.

\section{Conclusion and Discussion}

The global climate system is diverse at different spatialtemporal scales. Climate change adaptation measures adopted under any single spatial-temporal scale cannot fully reflect the relation between people and global climate diversity on various temporal and spatial scales. The global community must adopt various measures, especially with respect to improving the serviceability of ecological systems in global extreme-climate areas on the background of global climate change and enhancing the capability of coping with extreme climate and weather conditions. At present, most international countermeasures for adapting to global climate warming are only partial measures for global climate diversity adaptation and cannot represent all things for global climate change adaptation.

Since the dawn of humanity, human survival and development have been closely related to the earth's climate. Especially after the industrial revolution, human activities have affected the global climate. People and climate form an interdependent coexisting system on multiple scales. In such a system, with an increase in spatial and temporal scales, the human effect on the climate slows, but has a deep and longterm feature. Correspondingly, countermeasures implemented by the global community become more complicated and the action is slower. With a decrease in spatial and temporal scales, the human effect on the climate becomes more apparent, but uncertainty and social problems relating to politics, economy, law, ethics, and fairness still impede people from adopting correct and timely actions. People often learn how to live with climate diversity in the event of a disaster.
Improving the human ability to coexist with climate diversity requires common efforts by all people.

At present, it is difficult to improve people's ability to cope with global climate change risks, especially LSD risks related to climate diversity, on various spatial-temporal scales using global climate change risk governance measures based on a single spatial-temporal scale proposed by the international community. Therefore, it is imperative to establish a global integrated disaster risk governance framework according to the basic concept of establishing and improving a consilience strategy of LSD risk governance. This framework needs to cover several actions: comprehensive consideration of spatial-temporal scales and action dimensions to adapt to climate diversity; integration of measures for reducing vulnerability, improving resilience, and strengthening adaptability; undertaking structure optimization and function perfection actions for disaster prevention and reduction to enhance cohesion of disaster risk reduction; and taking globally important strategic countermeasures.

Establishing a global integrated disaster risk governance framework around the world requires us to organize and implement three globally important strategic countermeasures. First, we need to establish a global catastrophe governance foundation to fully utilize the leading function of the United Nations and national governments, extensively mobilize forces of enterprises and societies, and increase the efficiency and effectiveness of the United Nations' international disaster reduction activities and global LSD risk governance capability. Second, we need to establish a global green development union, to perfect "blue" strategy and "green" strategy for adapting to climate change, and equally treat emission reduction and economic development. Finally, we aim to establish a global climate change risk education and research network, to integrate related databases set up by relevant organizations of the United Nations, national governments, transnational insurance enterprises, scientific research institutes, institutions of higher learning, and social organizations. This will form a global information platform, and thoroughly enhance disaster prevention and reduction awareness, related skills, the science and technology level, and technological development through universities, scientific research institutions, and a community union.

However, coexisting with global climate diversity and establishing an integrated disaster risk governance framework not only requires cooperation between natural scientists and social scientists and strengthening of science and technology innovations, but also needs participation of all parts of societies. How can human society build consensus on several levels covering politics, economy, culture, and society? How can all possible forces be mobilized? How can the United Nations and national governments be encouraged to play a leading role? How can existing LSD governance enterprises be encouraged to play the demonstration role? Such problems demand a prompt solution. In recent years, various LSD coping practices in China and some developed Western countries have demonstrated that the integration of an all-country sys- 
tem from top to bottom and all-people system from bottom to top may be an important way of establishing the integrated disaster risk governance framework involving the unity of governments, enterprises, and societies.

\section{Acknowledgments}

This paper is based on research supported by grants from the National Key Basic Research and Development Program: Global and China Environmental Risk and Its Adaptation Paradigms (2012CB955404) and the International Science and Technology Cooperation Project from the Ministry of Science and Technology: Comparative Research on Integrated Risk Governance Technology and Paradigms in Typical Vulnerable Area (S2012GR0231).

\section{References}

Ban, Ki-moon. 2011. Foreword. Revealing Risk, Redefining Development. In 2011 Global Assessment Report on Disaster Risk Reduction. United Nations.

Diamond, J. 2005. How Societies Choose to Fail or Succeed. New York: Viking Press.

Huang, B. W., D. Zheng, and M. C. Zhao, eds. 1999. Modern Physical Geography. Beijing: Science Press (in Chinese).

IPCC (Intergovernmental Panel on Climate Change). 2007. Summary for Policymakers. In Climate Change 2007: The Physical Science Basis. Contribution of Working Group I to the Fourth Assessment Report of the Intergovernmental Panel on Climate Change, edited by S. Solomon, D. Qin, M. Manning, Z. Chen, M. Marquis, K. B. Averyt, M. Tignor, and H. L. Miller. Cambridge: Cambridge University Press.

Lass, W., A. Haas, J. Hinkel, and C. Jaeger. 2011. Avoiding the Avoidable: Towards a European Heat Waves Risk Governance. International Journal of Disaster Risk Science 2 (1): 1-14.

Meehl, G. A., T. F. Stocker, W. D. Collins, P. Friedlingstein, A. T. Gaye, J. M. Gregory, A. Kitoh, R. Knutti, J. M. Murphy, A. Noda, S. C. B. Raper, I. G. Watterson, A. J. Weaver, and Z. C. Zhao. 2007. Global
Climate Projections. In Climate Change 2007: The Physical Science Basis. Contribution of Working Group I to the Fourth Assessment Report of the Intergovernmental Panel on Climate Change, edited by S. Solomon, D. Qin, M. Manning, Z. Chen, M. Marquis, K. B. Averyt, M. Tignor, and H. L. Miller. Cambridge: Cambridge University Press.

Pielke, R., Sr. 2005. Land Use and Climate Change. Science 310 (5754): 1625-26.

Shi, P. J. 1989. Precipitation Change and "Fluctuation AgricultureAnimal Husbandry" in Transitional Agriculture-Animal Husbandry Zone in North China. Journal of Arid Land Resources and Environment 3 (3): 3-9 (in Chinese).

Shi, P. J., X. Q. Fang, and Y. Zhao. 1989. Research on Precipitation and Temperature Change in "Golden Triangle Area" of Inner Mongolia in the Past 500 Years. Journal of Arid Land Resources and Environment 3 (Supplement): 38-43 (in Chinese).

Shi, P. J., D. Tang, W. H. Fang, W. Xu, W. J. Dong, and B. Chen. 2008. Comments on Large-Scale Disaster Risk Governance Countermeasure from a Point of Coping with Cold, Rainy, Snowy and Freezing Weather Disasters in 2008 in China. Insurance Studies No. 5: 20-27 (in Chinese).

Shi, P. J., M. Wang, J. F. Liu, T. Ye, J. L. Nie, F. Kong, and Q. Q. Shi. 2011. An Integrated Large Scale Disaster Risk Governance Paradigm: Experiences and Lessons in Human Responses. In Proceedings of the 12th Biennial Aon Benfield Hazards Conference, 55-65. 29 September-1 October 2011, Surfers Paradise, Queensland, Australia.

Strahler, A. N., and A. H. Strahler. 1983. Modern Physical Geography. Beijing: Science Press (in Chinese).

Strahler, A. H., and A. N. Strahler. 1992. Modern Physical Geography, 4th edition. New York: John Wiley and Sons.

UNISDR (United Nations International Strategy for Disaster Reduction). n.d. UNISDR website. http://www.unisdr.org/. . 2004. Living with Risk. Geneva, Switzerland.

Wang, S. W. 1994. Introduction to Climate System. Beijing: China Meteorological Press (in Chinese).

Wu, G. H., L. S. Tian, S. X. Hu, and N. A. Wang. 2000. Physical Geography, 3rd edition. Beijing: Higher Education Press (in Chinese).

Zheng, D., and B. Y. Li. 1999. Differentiation and Evolution of Natural Environment in Qinghai-Tibet Plateau. In Modern Physical Geography, edited by B. W. Huang, D. Zheng, and M. C. Zhao, 234-58. Beijing: Science Press (in Chinese).

Zhou, S. Z., ed. 1997. Meteorology and Climatology, 3rd edition. Beijing: Higher Education Press (in Chinese).

Open Access This article is distributed under the terms of the Creative Commons Attribution License which permits any use, distribution, and reproduction in any medium, provided the original author(s) and source are credited. 